\title{
Synthesis of Nanosized Zinc-Doped Cobalt Oxyhydroxide Parties by a Dropping Method and Their Carbon Monoxide Gas Sensing Properties
}

\author{
Jian-Wen Wang and Yi-Ming Kuo \\ Department of Safety Health and Environmental Engineering, Chung Hwa University of Medical Technology, Tainan 717, Taiwan \\ Correspondence should be addressed to Jian-Wen Wang; jinwen.tw@yahoo.com.tw
}

Received 22 August 2012; Revised 21 December 2012; Accepted 23 December 2012

Academic Editor: Jinquan Wei

Copyright (C) 2013 J.-W. Wang and Y.-M. Kuo. This is an open access article distributed under the Creative Commons Attribution License, which permits unrestricted use, distribution, and reproduction in any medium, provided the original work is properly cited.

\begin{abstract}
Two nanostructures of cobalt oxyhydroxide ( $\mathrm{CoOOH})$ and Zinc-(Zn-) doped $\mathrm{CoOOH}(1-4 \% \mathrm{Zn})$ are prepared from $\mathrm{Co}\left(\mathrm{NO}_{3}\right)_{2}$ solution via microtitration with $\mathrm{NaOH}$ and oxidation in air. The X-ray diffraction (XRD) analysis results show that a pure state of nano-CoOOH can be obtained at an alkalinity $\left(\mathrm{OH}^{-} / \mathrm{Co}^{+}\right)$of 5 with $40^{\circ} \mathrm{C}$ heat treatment after $6 \mathrm{~h}$. The $\mathrm{Zn}$ ions preferentially substitute $\mathrm{Co}$ ions in the $\mathrm{CoOOH}$ structure, resulting in a decrease of its crystallinity. The disc-like $\mathrm{CoOOH}$ nanostructure exhibits good sensitivity to carbon monoxide (CO) in a temperature range of $40-110^{\circ} \mathrm{C}$ with maximum sensitivity to $\mathrm{CO}$ at around $70-80^{\circ} \mathrm{C}$. When $\mathrm{CoOOH}$ nanostructure is doped with $1 \% \mathrm{Zn}$, its sensitivity and selectivity for $\mathrm{CO}$ gas are improved at $70-80^{\circ} \mathrm{C}$; further $\mathrm{Zn}$ doping to $2 \%$ degraded the $\mathrm{CO}$ sensing properties of nano-CoOOH. The results of a cross-sensitivity investigation of the sensor to various gases coexisting at early stages of a fire show that the sensitivity of $\mathrm{Zn}$-doped nano-CoOOH is the highest toward CO. $\mathrm{Zn}$-doped nano- $\mathrm{CoOOH}$ film exhibits a high sensitivity to $\mathrm{CO}$ at room temperature, making it a promising sensor for early-stage fire detection.
\end{abstract}

\section{Introduction}

Fire detection systems are designed to respond to the smoke, heat, and electromagnetic radiation generated during smoldering and flaming combustion. It is known that decomposed gases, which are emitted in the preliminary stage of a fire, are generated before smoke. Therefore, numerous studies have developed gas sensors for fire detection [1]. Based on European standard EN 54, CO is a major by-product at early stages of a fire for all 6 typical fire scenarios [2]. Highly sensitive $\mathrm{CO}$ sensors can provide early fire detection and reduce false alarm rates [3].

Early fire detection requires that all major by-products of complete and/or incomplete combustion (including $\mathrm{CO}$ ) should be detected rapidly in a relatively low temperature range of $60-100^{\circ} \mathrm{C}$ (i.e., when a fire has just started). Several semiconducting metal oxides have been used in $\mathrm{CO}$ gas sensors, including $\mathrm{SnO}_{2}, \mathrm{ZnO}, \mathrm{Fe}_{2} \mathrm{O}_{3}, \mathrm{BaTiO}_{3}, \mathrm{TiO}_{2}, \mathrm{In}_{2} \mathrm{O}_{3}$, and $\mathrm{Zn}_{2} \mathrm{SnO}_{4}$ [4]. However, these $\mathrm{CO}$ gas sensors require relatively high operating temperatures (above $400^{\circ} \mathrm{C}$ ) [5-7]. Therefore, $\mathrm{CO}$ gas sensors that operate at a relatively low temperature are desirable.

$\mathrm{CoOOH}$ (cobalt oxyhydroxide), a high-conductivity active material used in conjunction with nickel hydroxide in $\mathrm{Ni}-\mathrm{H}$ cells, has been proposed as an alternative material for $\mathrm{CO}$ detection at low temperatures [8]. In contrast to $\mathrm{Co}_{3} \mathrm{O}_{4}, \mathrm{CoOOH}$ is a nonstoichiometric oxide; Co has a higher oxidation state $(+3)$ than that of $\mathrm{Co}_{3} \mathrm{O}_{4}(+2)$. Some studies on the oxidation of $\mathrm{CO}[9,10]$ have shown that cobalt Co $(+3)$ ions are active in the reaction. Results revealed that although response and recovery rates at low temperatures are an issue, the temperature for the maximum $\mathrm{CO}$ sensitivity level for $\mathrm{CoOOH}$ could be decreased down to $80^{\circ} \mathrm{C}$ [11].

Many approaches have been proposed for modifying the sensing properties of semiconductor oxide $\mathrm{CO}$ sensors to achieve high sensitivity and selectivity. Grain size reduction 
is another approach to enhancing gas sensitivity. Zhuiykov and Dowling [12] showed that dumbbell-like $\mathrm{CoOOH}$ nanostructures exhibit high sensitivity to $\mathrm{CO}$ at room temperature as well as good reproducibility and short response/recovery times. The gas sensitivity is expected to increase when the grain size becomes smaller than the space charge depth [13]. Thus, in this study, nanosized $\mathrm{CoOOH}$ was synthesized by a modified dropping method using a peristaltic pump to avoid excessive volume of sodium hydroxide solution drop into cobalt nitrate solution resulting in the rapid growth of precursor particles.

Noble metals (Ag, $\mathrm{Au}, \mathrm{Pt}$, and $\mathrm{Pd}$ ) are well known for enhancing the rate of response and increasing selectivity to a single gas. Shimizu and Egashira [14] indicated that $\mathrm{CO}$ sensitivity and selectivity of a nanostructured $\mathrm{CoOOH}$ $\mathrm{CO}$ sensor can be increased by Au nanoparticle addition. The results also showed that Au nanoparticles enhance the reaction kinetics at low temperature. In addition, Bahlawane et al. [15] indicated that the addition of nickel or zinc affects the conductivity of $\mathrm{Co}_{3} \mathrm{O}_{4}$, generating metal vacancies and decreasing resistivity. Similar results for the addition of $\mathrm{SnO}_{2}$ to $\mathrm{Co}_{3} \mathrm{O}_{4}$ sensor materials were reported [16]. $\mathrm{SnO}_{2}$ addition to $\mathrm{Co}_{3} \mathrm{O}_{4}$ leads to an increase in sensor resistance compared to that of undoped $\mathrm{Co}_{3} \mathrm{O}_{4}$. Thus, it was considered that similar promotion effects can be obtained for nano$\mathrm{CoOOH}$ doped by $\mathrm{Zn}$ or Ni. Therefore, we attempted to further improve the $\mathrm{CO}$ sensing properties by the development of a nanostructure of $\mathrm{CoOOH}$ doped with $\mathrm{Zn}$ in this study.

\section{Experimental Procedure}

2.1. Sample Preparation. In a typical synthesis of $\mathrm{CoOOH}$ nanomaterials, $100 \mathrm{~mL}$ of $2.5 \mathrm{M} \mathrm{NaOH}$ solution was added dropwise into $100 \mathrm{~mL}$ of $0.5 \mathrm{M}$ cobalt nitrate $\left(\mathrm{Co}\left(\mathrm{NO}_{3}\right)_{2} \cdot 6 \mathrm{H}_{2} \mathrm{O}\right)$ solution with a peristaltic pump to form a $\mathrm{Co}(\mathrm{OH})_{2}$ precursor. The $\mathrm{pH}$ value was kept below 9 during the mixing process. The red color of $\mathrm{Co}\left(\mathrm{NO}_{3}\right)_{2} \cdot 6 \mathrm{H}_{2} \mathrm{O}$ gradually changed to deep blue and finally to pink. When the $\mathrm{pH}$ was increased to $9<\mathrm{pH}<14$, the color of the $\mathrm{Co}(\mathrm{OH})_{2}$ precipitate turned brown with the formation $\mathrm{Co}(\mathrm{OH})_{3} \cdot \mathrm{CoOOH}$ was obtained from $\mathrm{Co}(\mathrm{OH})_{3}$ by holding in $40^{\circ} \mathrm{C}$ water bath for $1 \sim 6 \mathrm{hr}$. The final brown precipitate was filtered and washed with deionized water three times, then dried at $60^{\circ} \mathrm{C}$ for 2 days, and collected as $\mathrm{CoOOH}$.

$\mathrm{CoOOH}$ nanopowders doped with $\mathrm{Zn}$ were synthesized by a hydrothermal method. Some of the $\mathrm{CoOOH}$ nanopowders were ultrasonically dispersed into methanol $(200 \mathrm{~mL})$ at about $60^{\circ} \mathrm{C}$. Subsequently, $0.01 \mathrm{M} \mathrm{Zn}(\mathrm{Ac})_{2}$ was dissolved into the above solution. Then, a $0.03 \mathrm{M}$ solution of $\mathrm{KOH}(65 \mathrm{~mL})$ in methanol was added dropwise. The reaction mixture was stirred for $2 \mathrm{~h}$. The resulting solution was concentrated by the evaporation of the solvent. The resulting white product was centrifuged and then washed with deionized water and ethanol to remove any remaining ions in the final product. The $\mathrm{CoOOH}$ nanopowders doped with $\mathrm{Zn}$ of $\mathrm{Zn}$ : Co molar ratios of $0,1,2,3$, and $4 \%$ were prepared.

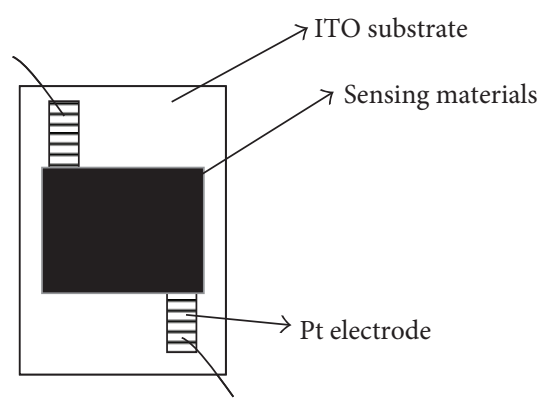

Connection to measurement circuit

Figure 1: Structure of sensing element.

2.2. Sample Characterization. Thermogravimetric/differential thermal analysis (TG/DTA) of the $\mathrm{CoOOH}$-based nanostructure was conducted using a differential thermal analyzer (Setaram Setsys Evolution 1600, France). A gas flow rate of $100 \mathrm{~cm}^{3} /$ min was maintained for all experiments. The temperature was increased at a rate of $10^{\circ} \mathrm{C} / \mathrm{min}$ from room temperature up to $1000^{\circ} \mathrm{C}$.

The crystalline phase was identified using an X-ray diffractometer (XRD, Model Rad IIA, Rigaku Co., Tokyo, Japan) with $\mathrm{Cu} \mathrm{K} \alpha$ radiation and an $\mathrm{Ni}$ filter, operated at $30 \mathrm{kV}, 20 \mathrm{~mA}$, and a scanning rate of $4^{\circ} / \mathrm{min}$. The surface morphology of the $\mathrm{CoOOH}$-based powders was examined by a field-emission scanning electron microscope (FE-SEM, XL40 FEG SEM, Philips, Eindhoven, Holland).

2.3. Gas Sensing Experiments. Sensing material was prepared in the form of a paste by mixing an appropriate amount of glycerol, $3 \mathrm{~g} \mathrm{CoOOH}$ or $\mathrm{Zn}$-doped $\mathrm{CoOOH}$ powder, and $1 \mathrm{~mL}$ tetraethyl orthosilicate (TEOS) binder. Nanostructured layers of $\mathrm{Zn}$-doped $\mathrm{CoOOH}$ and pure $\mathrm{CoOOH}$ were deposited onto indium tin oxide (ITO) substrates between attached Pt electrodes by using an organic binder. Figure 1 shows the structure of the sensing element.

Gas sensing experiments were carried out in a selfdesigned conventional flow apparatus equipped with heating facility. Each sensor was exposed to a constant flow of dry air $\left(100 \mathrm{~cm}^{3} / \mathrm{min}\right)$ or a sample gas (CO or other calibrated gases in dry air), while the electrical resistance of the sensor was monitored by an Agilent 34970A multimeter, which was connected to a PC. The sensor responses was defined as $S=R g / R a$ for pure $\mathrm{CoOOH}$ and $\mathrm{Zn}$-doped $\mathrm{CoOOH}$ nanostructures, where $\mathrm{Rg}$ and $\mathrm{Ra}$ denote the sensor electrical resistance in a sample gas and in air, respectively. Measurements were performed between room temperature and $100^{\circ} \mathrm{C}$ with $\mathrm{CO}$ content of $100 \mathrm{ppm}$. The temperature was carefully measured using a K-type thermocouple located adjacent to the $\mathrm{CO}$ sensor. The cross-sensitivity of the cobalt oxyhydroxide-based sensors to various gaseous pollutants that are usually by-products of fires was examined. A $100 \mathrm{ppm}$ concentration was chosen for all gases that included CO, except carbon dioxide. 


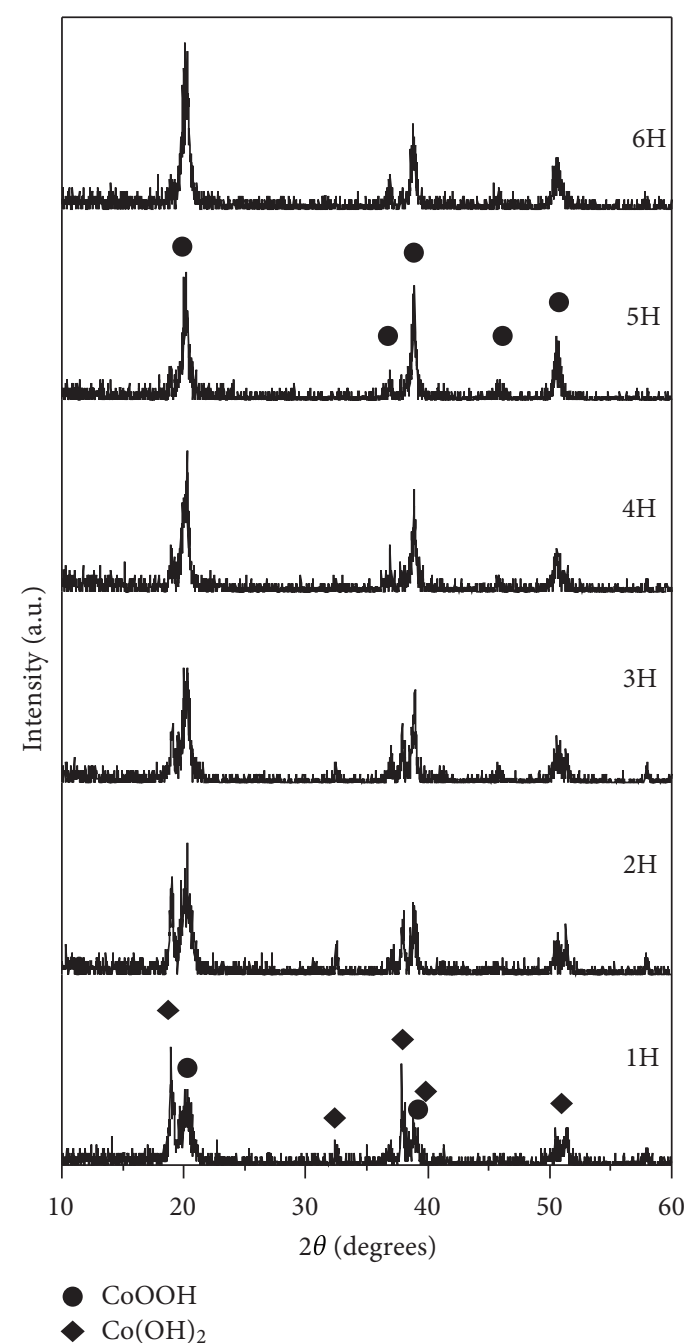

FIGURE 2: XRD patterns of cobalt oxide samples that underwent hydrothermal treatment at $40^{\circ} \mathrm{C}$ for various holding times.

\section{Results and Discussion}

3.1. Characterization of Nano-CoOOH. Figure 2 shows XRD patterns of cobalt oxide samples that underwent hydrothermal treatment at $40^{\circ} \mathrm{C}$ for various holding times. The main peaks were attributed to the $\mathrm{Co}(\mathrm{OH})_{2}$ structure after one hour. With increasing retention time, the peaks intensity of the $\mathrm{Co}(\mathrm{OH})_{2}$ structure decreased and then gradually transformed into those of the $\mathrm{CoOOH}$ phase. A pure phase of nanosized $\mathrm{CoOOH}$ can be obtained with a retention time of 5 $\mathrm{h}$ or longer. The results were verified by JCPD cards (JCPDC 14-0673).

Figures 3(a) and 3(b) show the morphology of $\mathrm{CoOOH}$ precursors and nanosized $\mathrm{CoOOH}$ prepared by hydrothermal treatment at $40^{\circ} \mathrm{C}$ for $6 \mathrm{~h}$, respectively. Figure 3(a) shows that the initial compound is composed of many nanoparticles that were created during the titration reaction. Since the surface energy of nanomaterials tends to aggregate in large particles, $\mathrm{CoOOH}$ precursors aggregated into an irregular plated form; the plate size was $50-150 \mathrm{~nm}$ in length and
$30-40 \mathrm{~nm}$ in width. However, some rod-like structures were scattered all over the corner region. They may be $\mathrm{CoOOH}$ nanostructures in a linear plated form. After hydrothermal treatment, $\mathrm{Co}(\mathrm{OH})_{3}$ transformed into a $\mathrm{CoOOH}$ structure. The surface morphology is shown in Figure 3(b). The $\mathrm{OH}$ functional groups were removed by the heating process, resulting in the irregular plate structure transforming into a disc-like structure. The particle size was $100-150 \mathrm{~nm}$ in diameter. The crystalline grain boundaries became obvious. The nanostructure increased the powder surface area and enhanced the sensitivity of the gas sensor.

Figure 4 shows TG/DTA measurements of nano- $\mathrm{CoOOH}$ in air. TGA data illustrate that after the initial loss of moisture, accumulated in the nanostructured $\mathrm{CoOOH}$, the loss of weight from 200 to $400^{\circ} \mathrm{C}$ was due to a gradual decomposition of $\mathrm{CoOOH} . \mathrm{Co}_{3} \mathrm{O}_{4}$ formed via the decomposition of $\mathrm{CoOOH}$, with $\mathrm{O}_{2}$ and $\mathrm{H}_{2} \mathrm{O}$ also produced, when the temperature was above $300^{\circ} \mathrm{C}$. Reaction (1) is an exothermic process, as confirmed by DTA analysis

$$
12 \mathrm{CoOOH} \longrightarrow 4 \mathrm{Co}_{3} \mathrm{O}_{4}+\mathrm{O}_{2}+6 \mathrm{H}_{2} \mathrm{O}
$$

$\mathrm{Co}_{3} \mathrm{O}_{4}$ was converted into $\mathrm{CoO}$ and $\mathrm{O}_{2}$ after a further increase of temperature via the following endothermic reaction:

$$
2 \mathrm{Co}_{3} \mathrm{O}_{4} \longrightarrow 6 \mathrm{CoO}+\mathrm{O}_{2}
$$

Reaction (2) is endothermic. $\mathrm{Co}_{3} \mathrm{O}_{4}$ is thermodynamically more stable than $\mathrm{CoO}$. The weight losses in reactions (1) and (2) are $10.36 \%$ and $6.1 \%$, respectively. The results obtained experimentally are in good agreement with the calculated values of $12.7 \%$ and $6.6 \%$, respectively.

3.2. Characterization of $\mathrm{Zn}$-Doped Nano-CoOOH. Figure 5 shows XRD patterns as a function of the $\mathrm{Zn}$ doping amount in the nano- $\mathrm{CoOOH}$ lattice. The refraction peaks of $\mathrm{CoOOH}$ can be indexed to a rhombohedral structure. As the amount of $\mathrm{Zn}^{2+}$ increases, the characteristic peak intensity of $\mathrm{CoOOH}$ decreases and additional peaks appear. The positions of the main diffraction peaks evidently shift to the smaller angle side with the increasing zinc content. This shift of diffraction angles indicates that $\mathrm{Zn}^{2+}$ ions have been successfully doped into the crystal lattice of $\mathrm{CoOOH}$ host. These phenomena can be explained in terms of the larger covalent radius of $\mathrm{Zn}^{2+}(0.74 \AA)$ than that of $\mathrm{Co}^{3+}(0.63 \AA)$. The $\mathrm{Zn}^{2+}$ ions doped into the $\mathrm{CoOOH}$ matrix necessarily results in the expansion of the unit-cell volume of the $\mathrm{Zn}$-doped $\mathrm{CoOOH}$ nanocrystals owing to the larger covalent radius of $\mathrm{Zn}^{2+}$ ions. In addition, the (003) peak exhibits significant broadening, which may be attributed to the disorder in the (003) side of $\mathrm{Zn}$-doped $\mathrm{CoOOH}$ nanocrystals. When the amount of $\mathrm{Zn}^{2+}$ was higher than $2 \%$, the characteristic peak (003) of $\mathrm{CoOOH}$ disappeared. This indicates that some $\mathrm{Zn}^{2+}$ did not enter the crystal lattice of $\mathrm{CoOOH}$, forming a $\mathrm{ZnO}$ structure. For $\mathrm{Zn}^{2+}$ doping amounts higher than $2 \%$, the crystallinity of $\mathrm{ZnO}$ increased. The changes in the structure from $\mathrm{CoOOH}$ to $\mathrm{ZnO}$ are not favorable for $\mathrm{CO}$ detection at low temperatures, as confirmed by electrical conductivity results of the materials. 


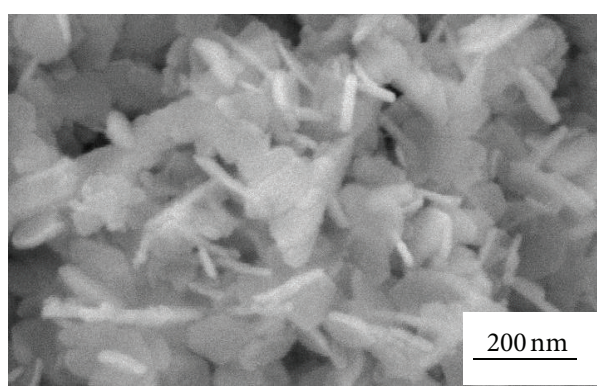

(a)

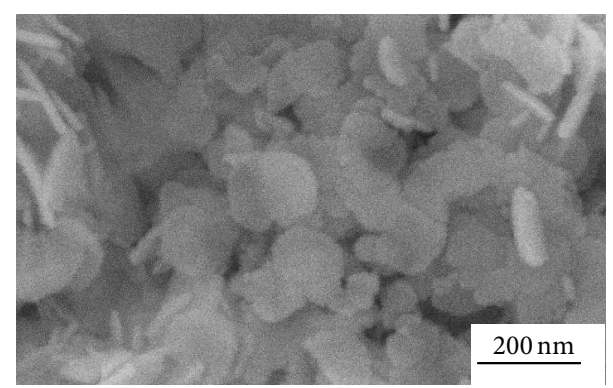

(b)

FIgure 3: Morphology of (a) $\mathrm{CoOOH}$ precursors and (b) nanosized $\mathrm{CoOOH}$ prepared by hydrothermal treatment at $40^{\circ} \mathrm{C}$ for $6 \mathrm{~h}$.

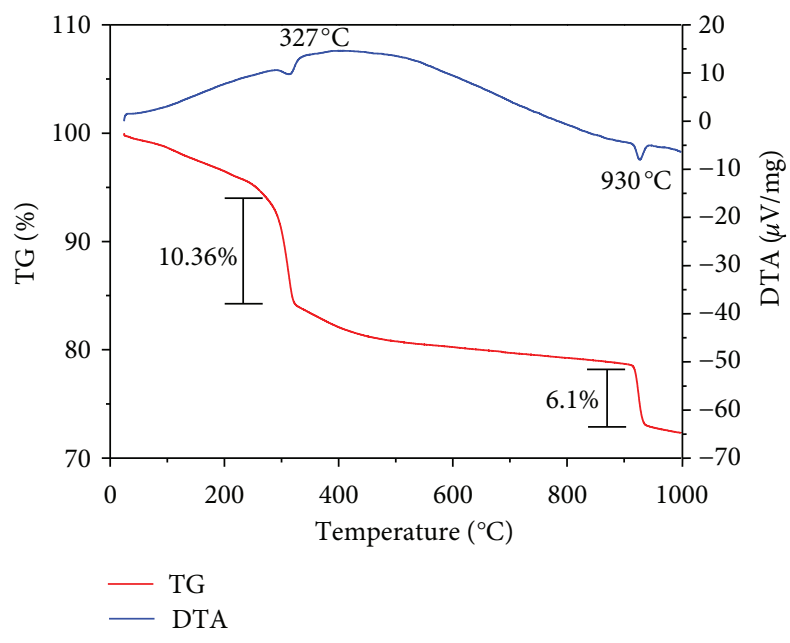

Figure 4: TG/DTA curves of the nano-CoOOH in air.

Figure 6 shows the surface morphology of nano- $\mathrm{CoOOH}$ with various $\mathrm{Zn}$ doping amounts. The plate and disclike structures of nano-CoOOH gradually transformed into spherical particles as the $\mathrm{Zn}$ doping amount increased from $1 \%$ to $2 \%$. When the $\mathrm{Zn}$ amount was increased to $3 \%$, the nanoparticle size decreased to $30-40 \mathrm{~nm}$ in diameter. However, the nanoparticles tended to aggregate and the particle size increased with the $\mathrm{Zn}$ doping amount for concentrations above $4 \%$. Some necking structures were found between particles. Added impurities may influence the size and morphology of a given crystal by participating in the nucleation and growth, in which many overall factors integrate to dominate the process. Meanwhile, the real behavior of crystal growth in nanocrystalline semiconductors may vary between fractal aggregation in the inauguration period and the subsequent diffusion process [17]. Change in morphology would be affected by the nucleation and growth process that would depend upon the above parameters as well as the charge status of the surface states and the dangling bonds. Compared to undoped sample, doped $\mathrm{CoOOH}$ nanocrystals shows individual grains clearly and its average particle size shrinks with different impurities.

Figure 7(a) shows TGA measurements of $\mathrm{Zn}$-doped nano- $\mathrm{CoOOH}$ in air. The nanocomplex in the range of

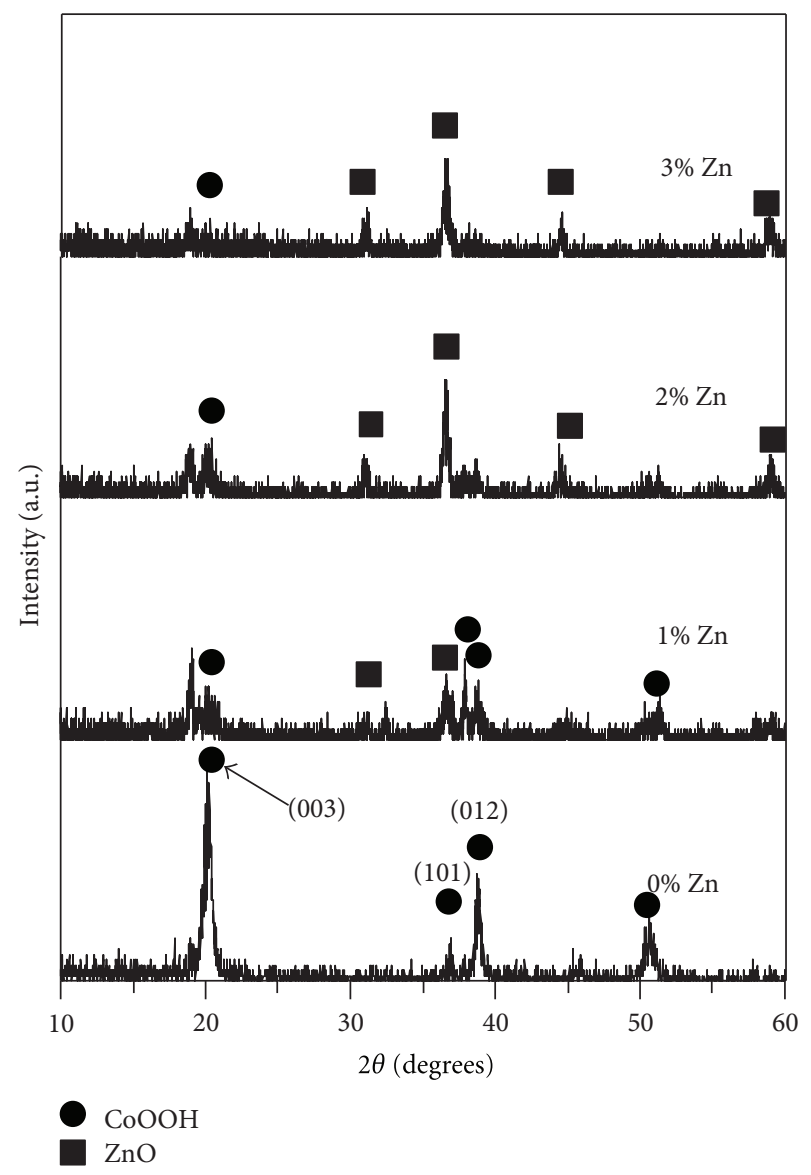

FIGURE 5: XRD patterns as a function of $\mathrm{Zn}$ doping amount in nano$\mathrm{CoOOH}$ lattice.

200-400 ${ }^{\circ} \mathrm{C}$ was the decomposition behavior similar to that of nano-CoOOH. It gradually lost its weight (6\%) when the $\mathrm{Zn}$ doping amount was $1 \%$. However, the weight loss of the nanocomplex significantly decreased (2\% and $0.3 \%)$ when the $\mathrm{Zn}$ doping amount was increased to $2 \%$ and $3 \%$. XRD analysis results confirm that $\mathrm{Zn}^{2+}$ doped into the crystal lattice $\mathrm{CoOOH}$ host, resulting in a significantly reduced amount of nano-CoOOH decomposition. Figure $7(\mathrm{~b})$ shows that the exothermic peak $\left(327^{\circ} \mathrm{C}\right)$ tended to decrease as the $\mathrm{Zn}$ doping amount increased. This indicates that the reaction that 


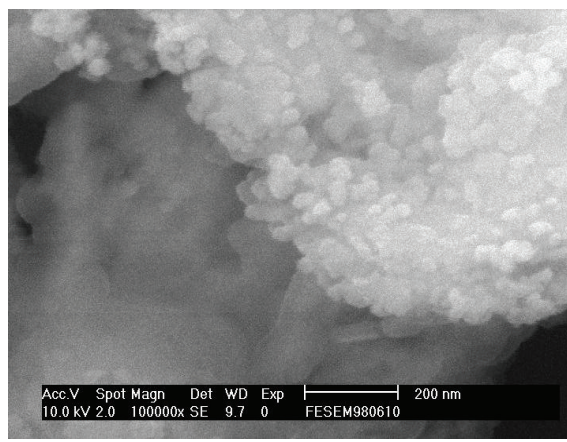

(a)

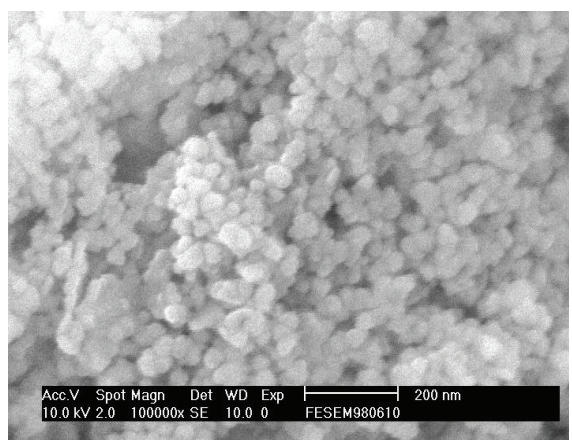

(c)

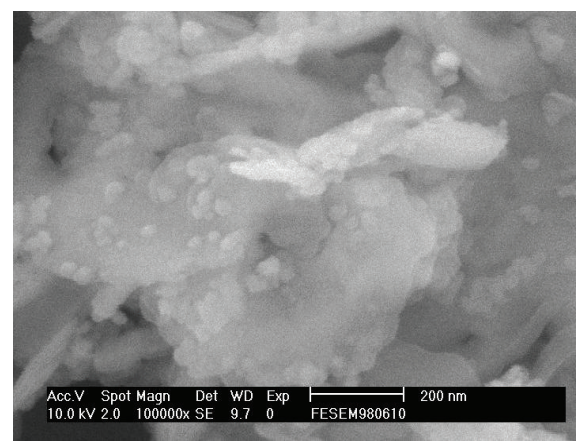

(b)

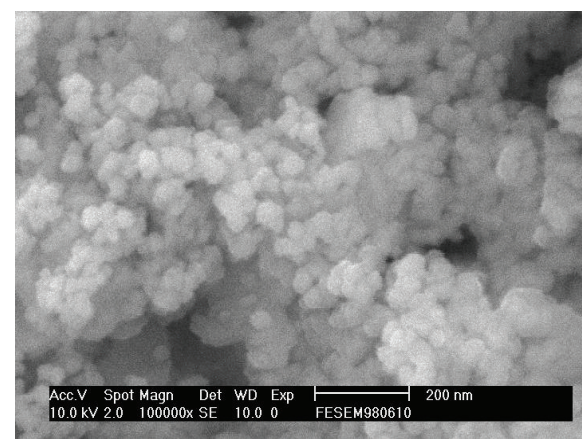

(d)

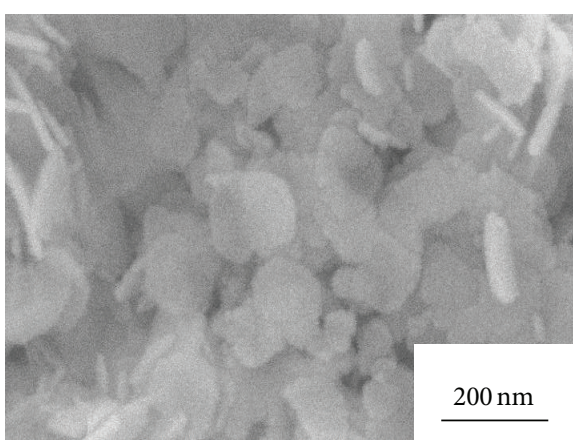

(e)

FIGURE 6: Surface morphologies of nano-CoOOH with Zn doping concentrations of (a) $1 \%$, (b) $2 \%$, (c) $3 \%$, (d) $4 \%$, and (e) $0 \%$.

transformed some $\mathrm{CoOOH}$ into $\mathrm{Co}_{3} \mathrm{O}_{4}$ gradually decreased as the $\mathrm{Zn}$ doping amount was increased. Moreover, during the first stage of $200-400^{\circ} \mathrm{C}$, there is weight loss about $6 \%$ to $0.3 \%$, indicating the formation of $\mathrm{Zn}_{x} \mathrm{Co}_{3-x} \mathrm{O}_{4}$ nanocomplex. The sharp weight loss at $930^{\circ} \mathrm{C}$ has been confirmed the complete decomposition of nanocomplex structure into $\mathrm{ZnO}$ and $\mathrm{CoO}[18]$. The $\mathrm{CoOOH}$ structure was disrupted when the $\mathrm{Zn}$ doping amount was above $2 \%$, resulting in a decrease of high-activity reaction areas of nano- $\mathrm{CoOOH}$.

According to the results of XRD, SEM, and TGA/DTA, the $\mathrm{Zn}$ doping amount was set to below 3\% for subsequent $\mathrm{CO}$ sensing tests.

3.3. Sensing Properties of Nano-CoOOH and $\mathrm{Zn}$-Doped Nano$\mathrm{CoOOH}$. Figure 8 shows the electrical resistance of nano$\mathrm{CoOOH}$ and $\mathrm{Zn}$-doped nano- $\mathrm{CoOOH}$ in air as a function of temperature in the range of $40-100^{\circ} \mathrm{C}$. The resistance of $\mathrm{CoOOH}$ increased with temperature in the range of 40 to $70^{\circ} \mathrm{C}$. However, the resistance of $\mathrm{CoOOH}$ decreased with temperature for temperatures over $70^{\circ} \mathrm{C}$. $\mathrm{CoOOH}$ can be regarded as a p-type semiconductor [19]. Therefore, the free electrons in $\mathrm{CoOOH}$ should become more active as the temperature increases, resulting in a decrease in the resistance of $\mathrm{CoOOH}$. However, the resistance of $\mathrm{CoOOH}$ increased with temperature in the range of 40 to $70^{\circ} \mathrm{C}$. According to Tobias et al. [20], $\mathrm{CoOOH}$ has a layered structure, and the high electrocatalytic activity of the inner sphere reactions on oxide materials is associated with surface defects. Active surface sites are found on step edges and corners of $\mathrm{CoOOH}$. In the range of $40-70^{\circ} \mathrm{C}$, the heat was insufficient to cause electron hopping in the layered structure, resulting in a conductive behavior of the metal oxide. However, when the 


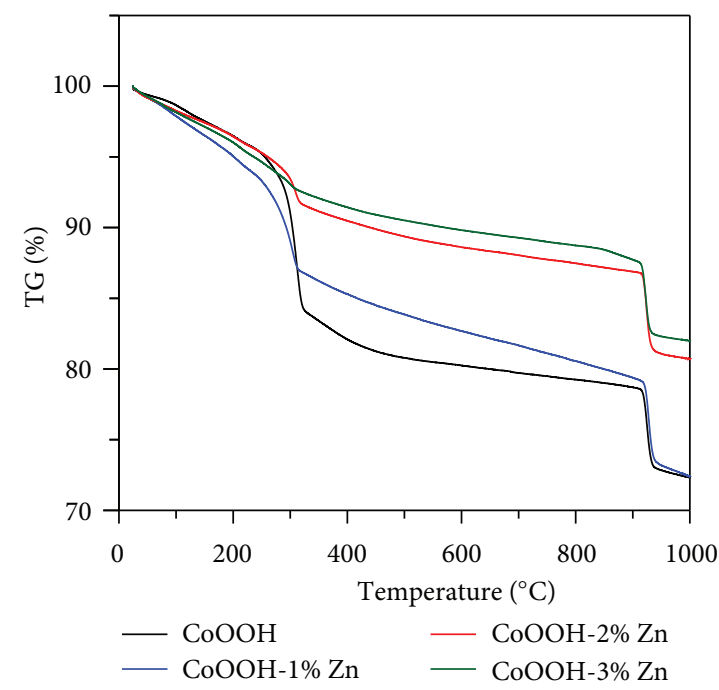

(a)

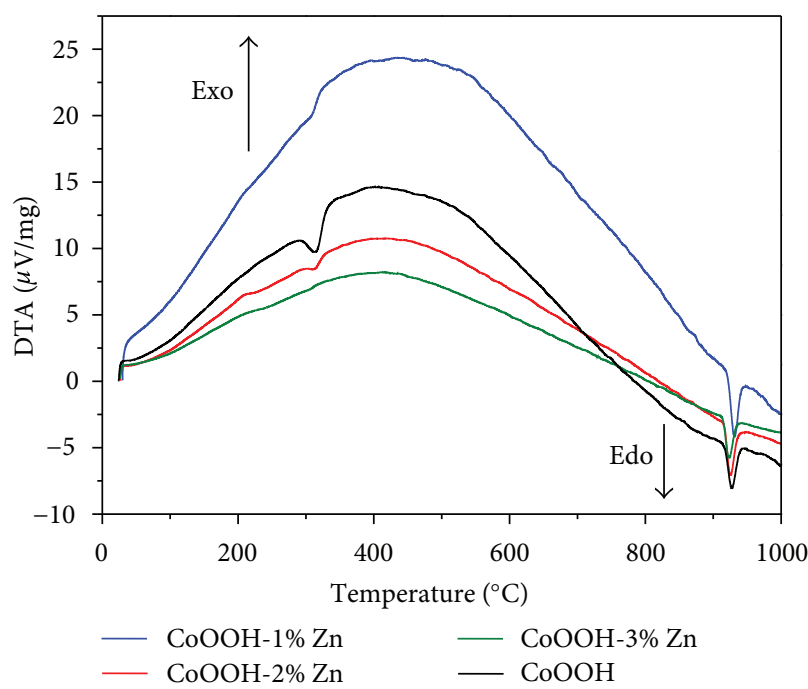

(b)

Figure 7: TGA/DTA curves of Zn-doped nano-CoOOH in air.

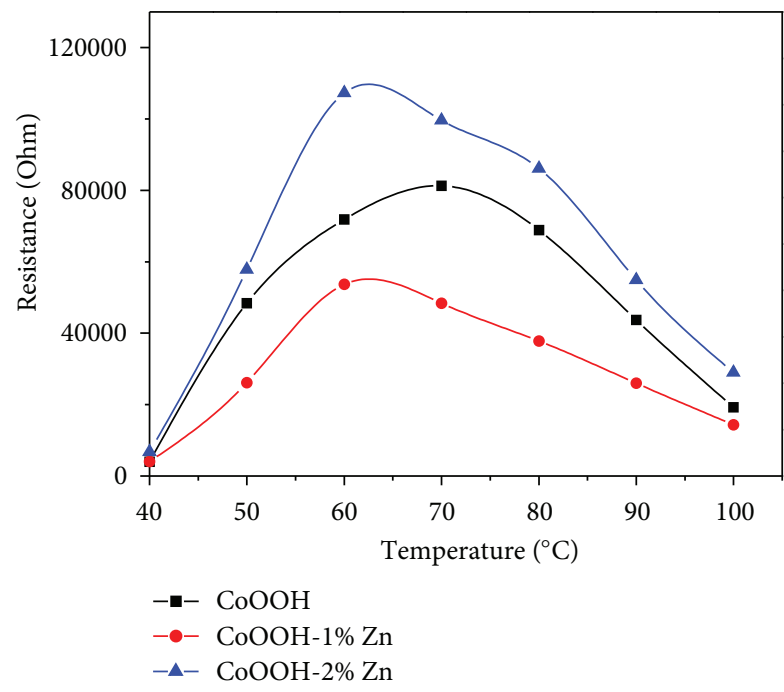

FIGURE 8: Electrical resistance of nano- $\mathrm{CoOOH}$ and $\mathrm{Zn}$-doped nano- $\mathrm{CoOOH}$ in air as a function of temperature in the range of $40-100^{\circ} \mathrm{C}$.

temperature was above $70^{\circ} \mathrm{C}$, the electrons hopped between the surface defects of $\mathrm{CoOOH}$, resulting in a decreased resistance. This behavior is similar to the semiconductor conduction mechanism.

Figure 8 also shows that the resistance of nano- $\mathrm{CoOOH}$ decreased with temperature when the $\mathrm{Zn}$ doping amount was increased to $1 \%$ in the range of 40 to $100^{\circ} \mathrm{C}$. However, the resistance of nano- $\mathrm{CoOOH}$ increased with temperature when the $\mathrm{Zn}$ doping amount was over $1 \%$. This indicates that appropriate zinc ion addition can reduce the resistance of nano-CoOOH. In addition, a low doping amount of zinc ions results in a small change in resistance with temperature. However, a rapid increase in resistance with temperature in the range of $60-70^{\circ} \mathrm{C}$ was found when the $\mathrm{Zn}$ doping amount was over $1 \%$. Excess zinc oxide formed in the $\mathrm{CoOOH}$ structure for a high $\mathrm{Zn}$ doping amount. Therefore, the electron hopping in the metal oxide was easily blocked, resulting in higher resistance. XRD analysis results confirm that the addition of zinc ions resulted in some structural distortion in $\mathrm{CoOOH}$. Hence, the conductivity of $\mathrm{Zn}$-doped $\mathrm{CoOOH}$ decreased with temperature in the range of 40 to $60^{\circ} \mathrm{C}$.

Figure 9 shows the sensor response to $1000 \mathrm{ppm} \mathrm{CO}$ in air for $\mathrm{CoOOH}$ and $\mathrm{Zn}$-doped nano- $\mathrm{CoOOH}$ as a function of temperature. $\mathrm{CoOOH}$ exhibited a larger response $(S=$ 6.87) over the temperature range of $70-80^{\circ} \mathrm{C}$. The $\mathrm{CO}$ sensing mechanism of $\mathrm{CoOOH}$ has been proposed to take the form of gas-phase $\mathrm{CO}$ adsorption and desorption at active sites on the nano-CoOOH surface and the form of a surface oxidation reaction between adsorbed $\mathrm{CO}$ and adsorbed oxygen atoms $\left(\mathrm{O}^{-}\right)$[21]. The surface oxidation reaction of $\mathrm{CO}^{-}$with $\mathrm{O}^{-}$produces $\mathrm{CO}_{2}$ (3). Therefore, the active vacant sites on the $\mathrm{CoOOH}$ surface decrease, resulting in a decreased conductivity

$$
\mathrm{CO}+\mathrm{O}^{-} \longrightarrow \mathrm{CO}_{2}+\mathrm{e}^{-}
$$

However, when the temperature exceeded $70^{\circ} \mathrm{C}$, the sensitivity of nano-CoOOH decreased with temperature. $\mathrm{CO}$ adsorption is an exothermic reaction, so it is unfavorable to proceed when the temperature exceeds a certain critical point. Therefore, the best operating temperature of nano$\mathrm{CoOOH}$ is $70-80^{\circ} \mathrm{C}$ for $\mathrm{CO}$ detection. Figure 9 also shows that the $\mathrm{CO}$ sensitivity of $\mathrm{Zn}$-doped nano-CoOOH-based devices initially increases with temperature, with maximum values $(S=7.88)$ at around $70^{\circ} \mathrm{C}$. The results presented in Figure 9 are consistent with similar results recently obtained by Wu et al. [22] and Zhuiykov [23]. However, the magnitude of the sensor response to $1000 \mathrm{ppm}$ CO for the nano$\mathrm{CoOOH}$ and $1 \% \mathrm{Zn}$-doped nano-CoOOH-based device was 


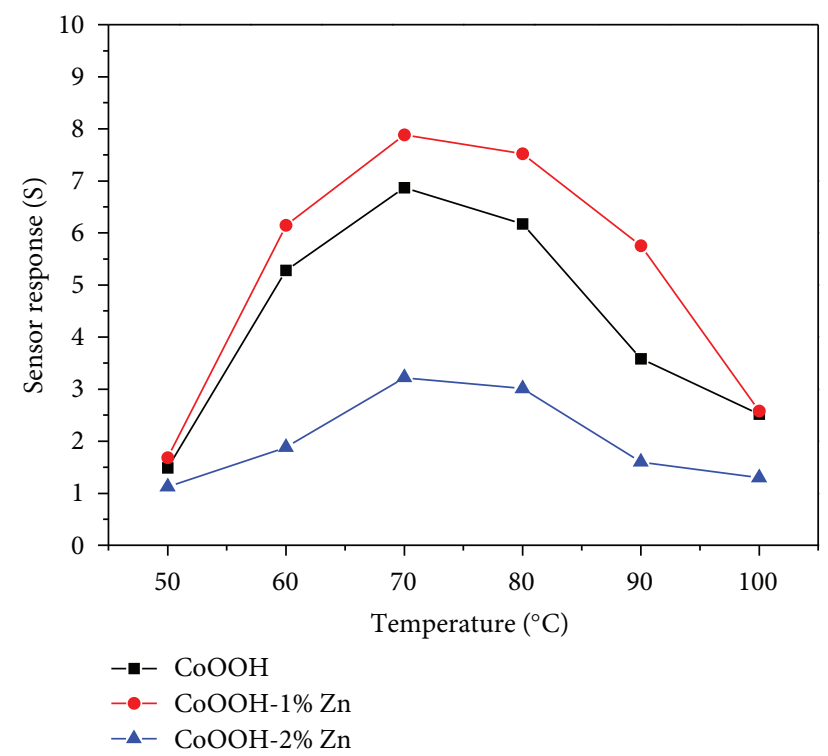

FIgURE 9: Sensor response to $1000 \mathrm{ppm} \mathrm{CO}$ in air for nano- $\mathrm{CoOOH}$ and $\mathrm{Zn}$-doped nano- $\mathrm{CoOOH}$ as a function of temperature.

greater than that for those $\mathrm{CoOOH}$ thin-film screen-printed on the alumina substrate. This is probably due to a much higher surface-to-volume ratio provided by nanotechnology [12]. For $\mathrm{Zn}$-doped nano-CoOOH, the maximum sensor response was obtained for the device doped with $1 \% \mathrm{Zn}$. $2 \% \mathrm{Zn}$ doping degraded the CO sensitivity substantially. The results obtained during this investigation agree with published results for an $\mathrm{H}_{2}$ sensor based on Co-doped $\mathrm{SnO}_{2}$ nanofibers [24]. With excess $\mathrm{Zn}$ content, the p-type characteristics of $\mathrm{CoOOH}$ regress, and the p-type response decreases accordingly. This indicates that $\mathrm{Zn}$ promotes the sensor response to $\mathrm{CO}$ until its content in the nanostructure exceeds a critical value.

The response and recovery time of sensors based on $1 \%$ $\mathrm{Zn}$-doped nano- $\mathrm{CoOOH}$ were investigated for different $\mathrm{CO}$ concentrations at a measuring temperature of $70^{\circ} \mathrm{C}$ as Figure 10 show. The sensor response changed rapidly from the base level upon switching to the different CO concentrations. The steady-state repeatable measuring values were attained at each measuring cycle. Typically, the $90 \%$ response and recovery times to $1000 \mathrm{ppm} \mathrm{CO}$ at an operating temperature of $70^{\circ} \mathrm{C}$ were 20 and $45 \mathrm{~s}$, respectively. A low working temperature of $70^{\circ} \mathrm{C}$ combined with high CO sensitivity of $1 \% \mathrm{Zn}$-doped nano- $\mathrm{CoOOH}$ as well as good response and recovery rate is very attractive for using cobalt oxyhydroxide as a sensor material for semiconductor $\mathrm{CO}$ sensors. The promoting effects of $\mathrm{Zn}$ in the present sensors are likely to be associated with the enhancement of the conductivity of $\mathrm{CoOOH}$ nanostructures. Figure 11 shows response changes as the $\mathrm{CO}$ concentration varies from 1 to $1000 \mathrm{ppm}$. It was revealed that the linearity of the line formed by plotting $\log S$ against $\log [\mathrm{CO}]$ was $R^{2}=0.9936$. The main effects of doping in $\mathrm{CoOOH}$ nanoparticles are the change in electronic conductivity and the introduction of defects into the nanoparticles. These factors play an important role

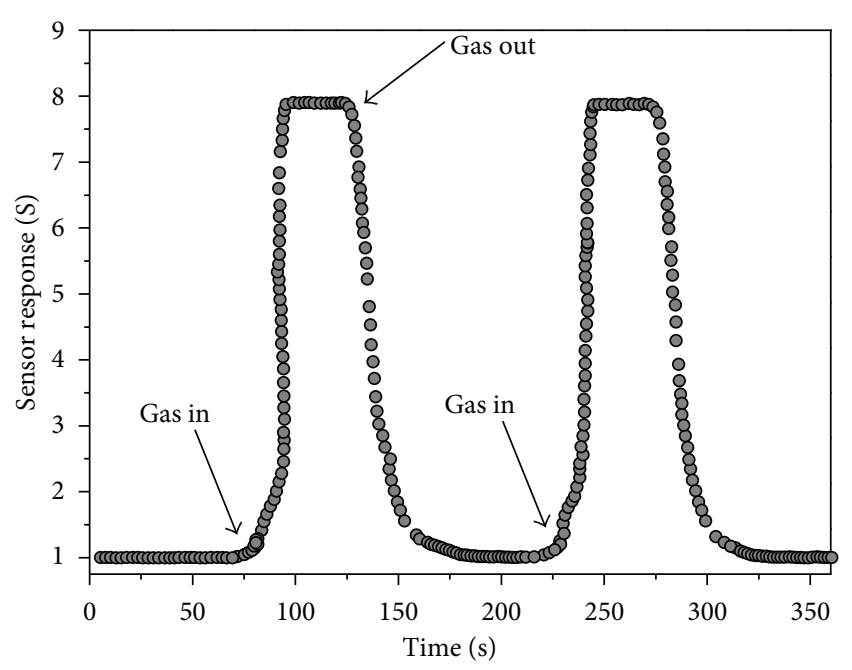

FIGURE 10: Response transients of $1 \% \mathrm{Zn}$-doped nano-CoOOH to $100 \mathrm{ppm} \mathrm{CO}$ at $70^{\circ} \mathrm{C}$.

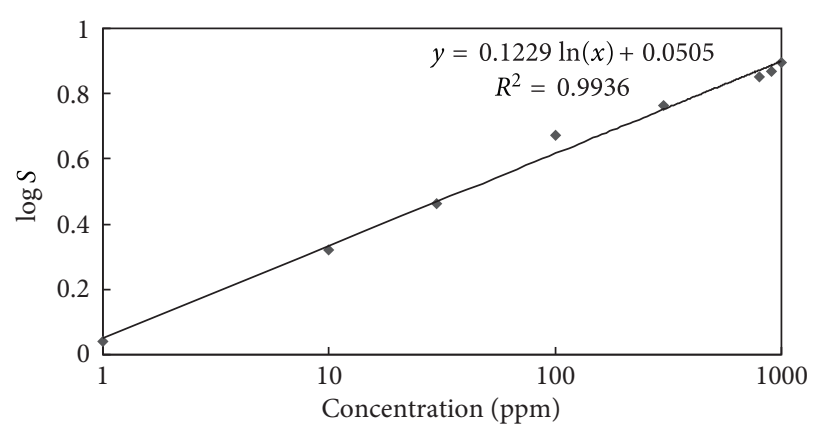

FIGURE 11: CO calibration curve of $1 \% \mathrm{Zn}$-doped nano-CoOOH sensor.

to enhance the sensitivity in nanoparticles sensors. Defects within the crystal structure can improve the adsorption of gas molecules on the nanoparticle surface and the change in the conductivity will change the position of Fermi level in the energy band diagram which governs the electronic transportation between gas molecule and nanoparticle material [25]. In addition, the electrical detection of any chemical species is dependent on the surface reactions between the nanoparticles and the chemical molecules. Since the amount of $\mathrm{Zn}$ insertion into the nanoparticles was found to be small (1\%), it is unlikely that solely chemical affinity can lead to the significant $\mathrm{CO}$ gas detection enhancement. Consequently, the interference effect experiments were carried out using for sensors based on $1 \% \mathrm{Zn}$-doped nano- $\mathrm{CoOOH}$.

3.4. Interference Effect of Nano-CoOOH and $\mathrm{Zn}$-Doped Nano$\mathrm{CoOOH}$. The cross-sensitivity of CO sensors based on nano$\mathrm{CoOOH}$ and $1 \% \mathrm{Zn}$-doped nano- $\mathrm{CoOOH}$ to various coexisting gases was investigated. The gases and method were chosen as described in the French Standard [26] because they are applicable to studies and investigations on the fire behavior of substances and materials. The sensor response to the gases was tested in addition to the sensor response to 


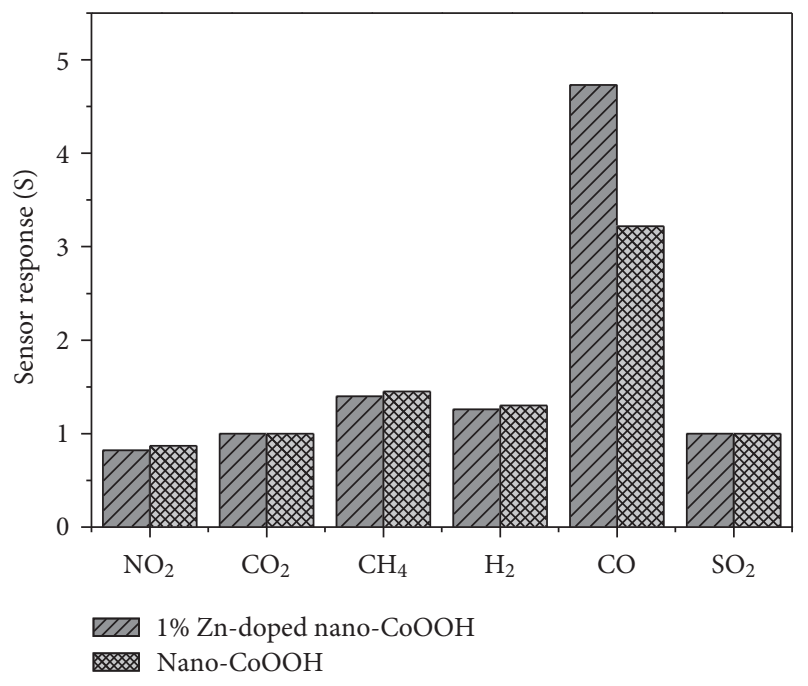

FIgURE 12: Cross-sensitivity of nano-CoOOH and 1\% Zn-doped nano- $\mathrm{CoOOH}$ sensors to gases typically found at early stages of a fire.

the coexisting gases $\left(\mathrm{NO}_{2}, \mathrm{CO}_{2}, \mathrm{CH}_{4}, \mathrm{H}_{2}\right.$, and $\left.\mathrm{SO}_{2}\right)$ typical for various fire scenarios. Figure 12 shows that sensors using $\mathrm{CoOOH}$ have a maximum response $(S=3.2)$ near $70^{\circ} \mathrm{C}$. At that temperature, the gases $\mathrm{NO}_{2}, \mathrm{CO}_{2}, \mathrm{CH}_{4}, \mathrm{H}_{2}$, and $\mathrm{SO}_{2}$ (all $100 \mathrm{ppm}$ ) exhibit low interference with $\mathrm{CO}$ gas in a nano- $\mathrm{CoOOH}$ sensor. The figure also shows that the relative response to $\mathrm{CO}$ and $\mathrm{H}_{2}\left(S_{\mathrm{CO}} / S_{\mathrm{H}_{2}}\right)$ of nano- $\mathrm{CoOOH}$ is near $2.5(2.46)$ at $70^{\circ} \mathrm{C}$. Therefore, the nanostructures enhance the sensitivity and selectivity of the reaction. Figure 9 also shows that sensors using $\mathrm{Zn}$-doped $\mathrm{CoOOH}$ have a maximum response $(S=4.73)$ near $70^{\circ} \mathrm{C}$. Furthermore, the relative response to $\mathrm{CO}$ and $\mathrm{H}_{2}\left(\mathrm{~S}_{\mathrm{CO}} / \mathrm{S}_{\mathrm{H}_{2}}\right)$ of $\mathrm{Zn}$-doped $\mathrm{CoOOH}$ is near to 4 (3.64). It seems that the addition of zinc ions can effectively increase the sensitivity and selectivity for the $\mathrm{CO}$ gas. According to Potyrailo et al. [27], different parts of the nanoscales can affect the overall measurement upon interaction with different types of gaseous molecules, producing remarkably diverse and distinct differential reactions in real fire situations. Therefore, obtaining the required scale of the $\mathrm{CoOOH}$ is the keyto achieving a highly selective response to individual gaseous molecules.

\section{Conclusion}

$\mathrm{CoOOH}$-based nanocomplexes were prepared from a $\mathrm{Co}\left(\mathrm{NO}_{3}\right)_{2}$ solution via a modified dropping method with $\mathrm{NaOH}$ and oxidation in air. The optimum working temperature of the $\mathrm{CoOOH}$ material for $\mathrm{CO}$ detection was roughly $70^{\circ} \mathrm{C}(S=6.87)$. $\mathrm{Zn}$ doping enhanced the $\mathrm{CO}$ sensitivity of the $\mathrm{CO}$ sensor based on nano-CoOOH. $\mathrm{Zn}$ doping concentrations of $1 \%$ to $2 \%$ improved the reaction mechanism at a low temperature. $\mathrm{Zn}$-doped nano- $\mathrm{CoOOH}$ exhibited a higher $\mathrm{CO}$ response than that of nano- $\mathrm{CoOOH}$. The optimal CO sensing was obtained when the sensor was operated at $70^{\circ} \mathrm{C}$, at which the sample exhibited a large response $(S=7.88)$ to $100 \mathrm{ppm} \mathrm{CO}$. The $\mathrm{Zn}$-doped nano$\mathrm{CoOOH}$ also exhibited a high selectivity for $\mathrm{CO}$ relative to $\mathrm{H}_{2}\left(S_{\mathrm{CO}} / S_{\mathrm{H}_{2}} \sim 4\right)$ in the $\mathrm{CO}$ concentration of $100 \mathrm{ppm}$. Zn-doped nano-CoOOH film exhibits high sensitivity and selectively to $\mathrm{CO}$ at room temperature, making it suitable for early fire detection.

\section{Acknowledgment}

The authors acknowledge the National Science Council of Taiwan, for financial support under Grant NSC 101-2221-E273-003-MY2.

\section{References}

[1] Y. Watabe, T. Hujioka, N. Yamaga et al., "Application of micro-electrochemical CO sensor using solid electrolyte to fire detection," in Digest of the 15th Chemical Sensor Symposium B, vol. 8, pp. 53-56, 1992.

[2] EN 54 Standard, Fire Detection and Fire Alarm Systems, Part 7, British Standards Institute, 2001.

[3] B. C. Hagen and J. A. Milke, "Use of gaseous fire signatures as a mean to detect fires," Fire Safety Journal, vol. 34, no. 1, pp. 55-67, 2000.

[4] J. H. Du, R. C. Zhang, X. Y. Huang, X. Gong, and X. H. Zhang, "Research on early fire detection with $\mathrm{CO}-\mathrm{CO}_{2}$ FTIRspectroscopy," Spectroscopy and Spectral Analysis, vol. 27, no. 5, pp. 899-903, 2007.

[5] J. H. Sung, Y. S. Lee, J. W. Lim, Y. H. Hong, and D. D. Lee, "Sensing characteristics of tin dioxide/gold sensor prepared by coprecipitation method," Sensors and Actuators, B, vol. 66, no. 1-3, pp. 149-152, 2000.

[6] P. Nellia, U. G. Fagliaa, G. Sberveglieria et al., "The aging effect on $\mathrm{SnO}_{2}$-Au thin film sensors: electrical and structural characterization," Thin Solid Films, vol. 371, no. 1-2, pp. 249-253, 2000.

[7] K. Fukui and S. Nishida, "A theoretical treatment of molecular complexes i silver-aromatic hydrocarbon complexes," Bulletin of the Chemical Society of Japan, vol. 34, pp. 1076-1080, 1961.

[8] W. K. Hu, X. P. Gao, M. M. Geng, Z. X. Gong, and D. Noréus, "Synthesis of $\mathrm{CoOOH}$ nanorods and application as coating materials of nickel hydroxide for high temperature $\mathrm{Ni}-\mathrm{MH}$ cells," Journal of Physical Chemistry B, vol. 109, no. 12, pp. 5392-5394, 2005.

[9] J. Jansson, A. E. C. Palmqvist, E. Fridell et al., "On the catalytic activity of $\mathrm{Co}_{3} \mathrm{O}_{4}$ in low-temperature $\mathrm{CO}$ oxidation," Journal of Catalysis, vol. 211, no. 2, pp. 387-397, 2002.

[10] F. Grillo, M. M. Natile, and A. Glisenti, "Low temperature oxidation of carbon monoxide: the influence of water and oxygen on the reactivity of a $\mathrm{Co}_{3} \mathrm{O}_{4}$ powder surface," Applied Catalysis B, vol. 48, no. 4, pp. 267-274, 2004.

[11] S. Mountford, "A sprinkler in the works," Fire Prevention, no. 366, pp. 48-49, 2003.

[12] S. Zhuiykov and V. Dowling, "The nanostructured Au-doped cobalt oxyhydroxide based carbon monoxide sensor for fire detection at its earlier stages," Measurement Science and Technology, vol. 19, no. 2, Article ID 024001, 2008.

[13] B. Geng, F. Zhan, H. Jiang, Z. Xing, and C. Fang, "Facile production of self-assembly hierarchical dumbbell-like $\mathrm{CoOOH}$ nanostructures and their room-temperature CO-gas-sensing properties," Crystal Growth and Design, vol. 8, no. 10, pp. 3497-3500, 2008. 
[14] Y. Shimizu and M. Egashira, "Basic aspects and challenges of semiconductor gas sensors," MRS Bulletin, vol. 24, no. 6, pp. 18-24, 1999.

[15] N. Bahlawane, P. A. Premkumar, J. Feldmann, and K. KohseHöinghaus, "Preparation of doped spinel cobalt oxide thin films and evaluation of their thermal stability," Chemical Vapor Deposition, vol. 13, no. 2-3, pp. 118-122, 2007.

[16] U. S. Choi, G. Sakai, K. Shimanoe, and N. Yamazoe, "Sensing properties of $\mathrm{SnO}_{2}-\mathrm{Co}_{3} \mathrm{O}_{4}$ composites to $\mathrm{CO}$ and $\mathrm{H}_{2}$," Sensors and Actuators, B, vol. 98, no. 2-3, pp. 166-173, 2004.

[17] K. Jayanthi, S. Chawla, K. N. Sood, M. Chhibara, and S. Singh, "Dopant induced morphology changes in $\mathrm{ZnO}$ nanocrystals," Applied Surface Science, vol. 255, no. 11, pp. 5869-5875, 2009.

[18] B. Chi, H. Lin, and J. Li, "Cations distribution of $\mathrm{Cu}_{x} \mathrm{Co}_{3-x} \mathrm{O}_{4}$ and its electrocatalytic activities for oxygen evolution reaction," International Journal of Hydrogen Energy, vol. 33, no. 18, pp. 4763-4768, 2008.

[19] R. J. Wu, J. G. Wu, T. K. Tsai, and C. T. Yeh, "Use of cobalt oxide $\mathrm{CoOOH}$ in a carbon monoxide sensor operating at low temperatures," Sensors and Actuators, B, vol. 120, no. 1, pp. 104-109, 2006.

[20] J. R. Tobias Johnsson Wass, I. Panas, J. Ásbjörnsson, and E. Ahlberg, "Quantum chemical modelling of oxygen reduction on cobalt hydroxide and oxyhydroxide," Journal of Electroanalytical Chemistry, vol. 599, no. 2, pp. 295-312, 2007.

[21] H. Gong, J. Q. Hu, J. H. Wang, C. H. Ong, and F. R. Zhu, "Nanocrystalline $\mathrm{Cu}$-doped $\mathrm{ZnO}$ thin film gas sensor for CO," Sensors and Actuators, B, vol. 115, no. 1, pp. 247-251, 2006.

[22] R. J. Wu, W. C. Chang, K. M. Tsai, and J. G. Wu, “The Novel $\mathrm{CO}$ sensing material $\mathrm{CoOOH}-\mathrm{WO}_{3}$ with $\mathrm{Au}$ and SWCNT performance enhancement," Sensors and Actuators, B, vol. 138, no. 1, pp. 35-41, 2009.

[23] S. Zhuiykov, "Carbon monoxide detection at low temperatures by semiconductor sensor with nanostructured $\mathrm{Au}$-doped CoOOH films," Sensors and Actuators, B, vol. 129, no. 1, pp. 431-441, 2008.

[24] L. Liu, C. Guo, S. Li, L. Wang, Q. Dong, and W. Li, "Improved $\mathrm{H}_{2}$ sensing properties of Co-doped $\mathrm{SnO}_{2}$ nanofibers," Sensors and Actuators, B, vol. 150, no. 2, pp. 806-810, 2010.

[25] N. Singh, C. Yan, and P. S. Lee, "Room temperature CO gas sensing using $\mathrm{Zn}$-doped $\mathrm{In}_{2} \mathrm{O}_{3}$ single nanowire field effect transistors," Sensors and Actuators, B, vol. 150, no. 1, pp. 19-24, 2010.

[26] NF X 70-100 French Standard, "Fire Tests: analysis of pyrolysis and combustion gases," ANFOR, pp. 51, 1986.

[27] R. A. Potyrailo, H. Ghiradella, A. Vertiatchikh, K. Dovidenko, J. R. Cournoyer, and E. Olson, "Morpho butterfly wing scales demonstrate highly selective vapour response," Nature Photonics, vol. 1, no. 2, pp. 123-128, 2007. 

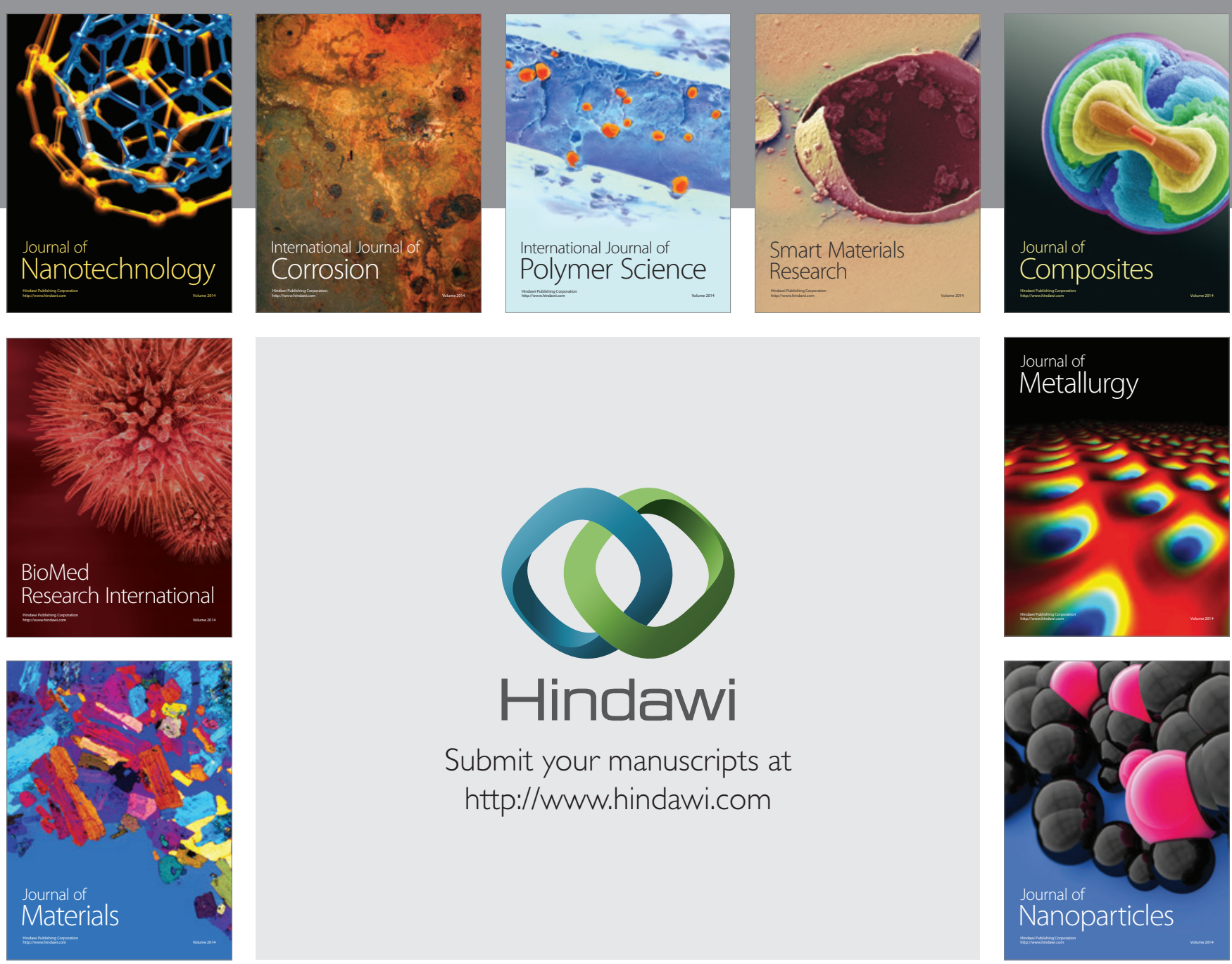

Submit your manuscripts at http://www.hindawi.com
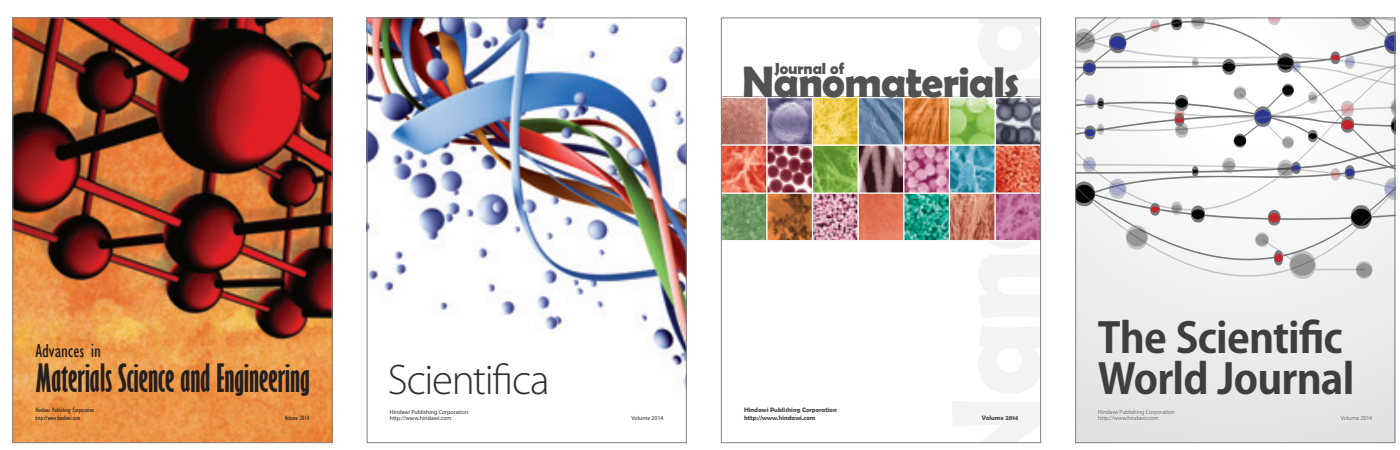

\section{The Scientific World Journal}
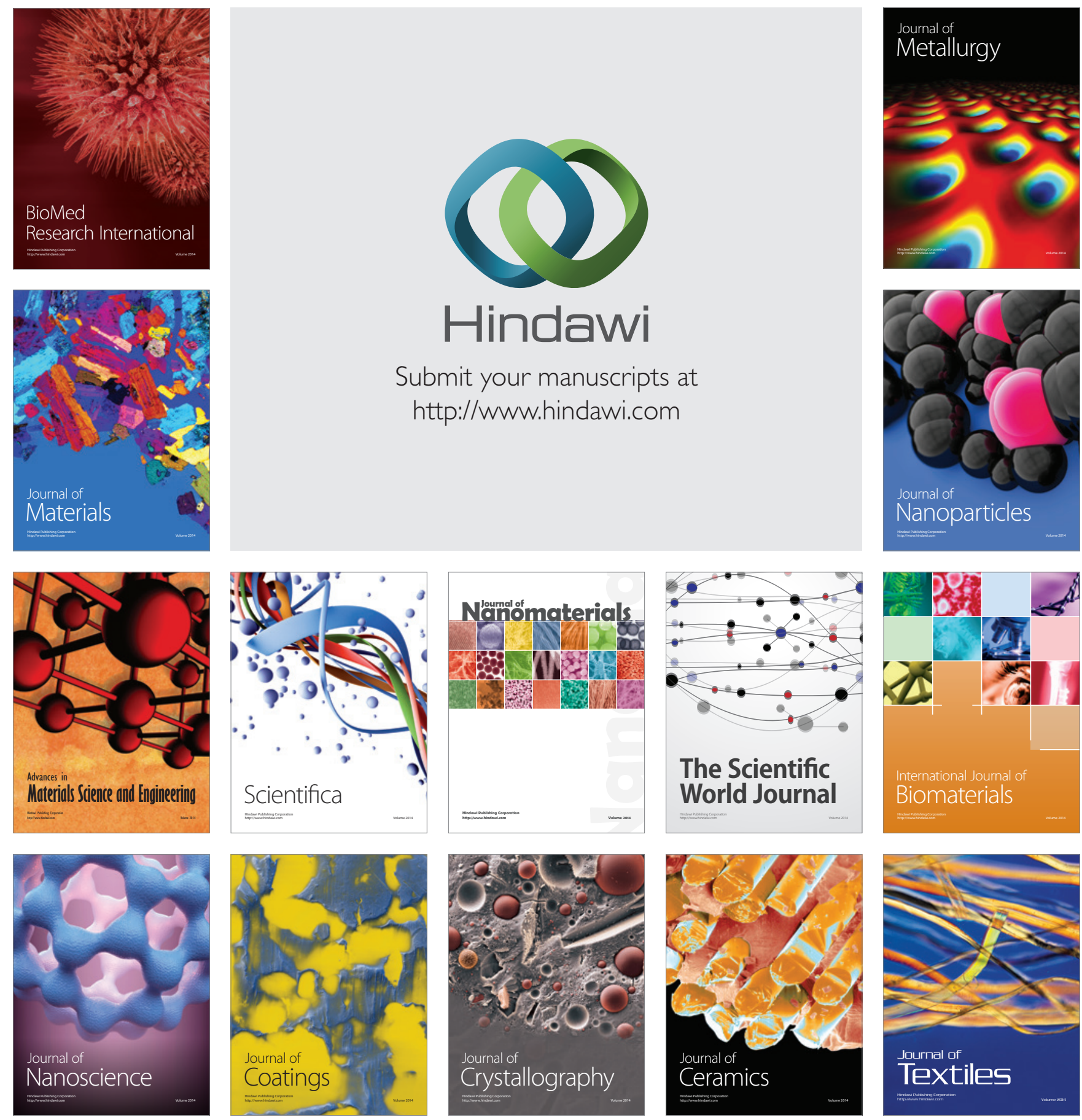